\title{
ESTANDARIZACIÓN Y VALIDACIÓN DE LA PRUEBA DE PCR ANIDADA PARA EL DIAGNÓSTICO DE ESPECIES DEL GÉNERO XYLEBORUS (COLEOPTERA: CURCULIONIDAE: SCOLYTINAE)
}

\author{
STANDARDIZATION AND VALIDATION OF THE NESTED PCR TEST FOR THE DIAGNOSIS \\ OF THE GENUS XYLEBORUS SPECIES (COLEOPTERA: CURCULIONIDAE: SCOLYTINAE)
}

\section{María Elena SOSA-CASTILlo,${ }^{1}$ Joel LARA REYNA,${ }^{2}$ Laura Delia ORTEGA ARENAS ${ }^{1, *}$ y Alfonsina JUDITH HERNÁNDEZ ${ }^{3}$}

\author{
${ }^{1}$ Fitosanidad, Entomología y Acarología, Colegio de Postgraduados, Campus Montecillo. km 36.5 Carretera \\ México-Texcoco, 56230, Montecillo, Texcoco, Edo. de México, México. <ladeorar@colpos.mx ><alfonsina@ \\ colpos.mx> \\ ${ }^{2}$ Colegio de Postgraduados, Campus Campeche. km 17.5 Carretera Haltunchén-Edzna, 24450, Champotón, \\ Campeche, México.<jlara@colpos.mx> \\ ${ }^{3}$ Fitopatología, Colegio de Postgraduados, Campus Montecillo. km 36.5 Carretera México-Texcoco, 56230, \\ Montecillo, Texcoco, Edo. de México, México. \\ * Autor para correspondencia: Laura Delia Ortega Arenas <ladeorar@colpos.mx> \\ Recibido: 28/01/2016; aceptado: 15/09/2016 \\ Editor responsable: Carmen Huerta
}

Sosa-Castillo, M. E., Lara-Reyna, J., Ortega-Arenas, L. D. y Judith-Hernández, A. (2017) Estandarización y validación de la prueba de PCR anidada para el diagnóstico de especies del género Xyleborus (Coleoptera: Curculionidae: Scolytinae). Acta Zoológica Mexicana (n.s.), 33(1), 18-26.

RESUMEN. En este estudio se estandarizó y validó la técnica de PCR anidada para la detección rápida, sensible y confiable de especies del género Xyleborus mediante el uso de los "primers" externos CI-J-2183 y TL2-N-3014 e internos J2210 y N2739, que amplifican una banda de $500 \mathrm{pb}$ de la región del gen mitocondrial Citocromo Oxidasa subunidad 1(CO1). Asimismo, se realizó la extracción de ADN de 26 ejemplares de Xyleborus con el kit Qiagen DNeasy ${ }^{\circledR}$ mericom Food (DMF), no reportado previamente su uso para su aplicación en insectos, que resultó en ADN suficiente y de alta calidad para reacciones de amplificación por PCR. El método permitió procesar un solo insecto por extracción, y obtener material genético de muestras conservadas en alcohol de hasta ocho años de antigüedad. El límite de detección se definió hasta una concentración de $780 \mathrm{pg} / \mu \mathrm{l}$. Se optimizó la PCR en un volumen final de $15 \mu \mathrm{L}$ sin comprometer calidad de la amplificación. La técnica estandarizada permitió la obtención de ADN de calidad, lo que aseguró alta reproducibilidad y sensibilidad en la detección de especies de Xyleborus y la secuenciación parcial del gen CO1 para las siete especies estudiadas; las secuencias consenso fueron analizadas por homología y depositadas en el GenBank.

Palabras clave: Escarabajos ambrosiales, identificación molecular, diagnóstico, gen $\mathrm{CO} 1$.
Sosa-Castillo, M. E., Lara-Reyna, J., Ortega-Arenas, L. D., \& Judith-Hernández, A. (2017) Standardization and validation of the nested PCR test for the diagnosis of the genus Xyleborus species (Coleoptera: Curculionidae: scolytinae). Acta Zoológica Mexicana (n.s.), 33(1), 18-26.

ABSTRACT. In this study it was standardized and validated the nested PCR test for rapid, sensitive and reliable detection of species of the genus Xyleborus using external "primers" CI-J-2183 and TL2-N-3014 and internal primers J2210 and N2739 that amplify a band of $500 \mathrm{bp}$ in the region of the gene mitochondrial Cytochrome Oxidase subunit 1(CO1). Also, DNA extraction from 26 specimens of Xyleborus was realized with kit Qiagen DNeasy ${ }^{\circledR}$ mericom Food (DMF), not previously reported its use for their application in insects, which resulted in enough DNA and high-quality for amplification by PCR reactions. The method allowed to process a single insect by extraction, and obtain genetic material from specimens preserved in alcohol of up to eight years old. The detection limit was defined up to a concentration of 780 $\mathrm{pg} / \mu \mathrm{L}$. The PCR was optimized in a final volume of $15 \mu \mathrm{L}$ without compromising quality of amplification. The standardized test allowed quality DNA, which ensured high reproducibility and sensitivity in the detection of species of Xyleborus and partial sequencing of the CO1 gene to the seven species studied; consensus sequences were analyzed by homology and deposited in the GenBank.

Key words: Ambrosial beetles, molecular identification, diagnosis, CO1 gene. 


\section{INTRODUCCIÓN}

La apertura de México al libre comercio ha incrementado el riesgo de la introducción de plagas exóticas, que por sus características fisiológicas causan pérdidas económicas, de salud y ambientales (FAO-IPPC 2007). Actualmente, en diversos cultivos de interés económico, se tienen bajo vigilancia 31 plagas identificadas como de alto riesgo, entre las que se encuentran el complejo de escarabajos ambrosiales o escolítidos del género Xyleborus (Coleoptera: Curculionidae: Scolytinae) (SENASICA 2015). La información relativa a especies de Xyleborus en México ha ido en aumento debido a que algunas especies representan riesgo para algunos árboles de importancia económica, tal es el caso de Xyleborus affinis (Eichhoff, 1868), X. ferrugineus (Fabricius, 1801), X. volvulus (Fabricius, 1775) y $X$. glabratus (Eichhoff, 1877). Esta última, aunque no se encuentra reportada en México, es considerada plaga potencial debido a que actúa como vector primario del hongo patógeno Raffaelea lauricola T.C. Harr., Fraedrich \& Aghayeva que causa la "marchitez del laurel", una enfermedad vascular letal para las plantaciones de aguacate Persea americana Mill. Lauraceae (Pérez et al. 2015b). La rápida dispersión de la plaga en EUA, aunado a la amplia disposición de hospederos susceptibles en varias entidades de México (Loera 2014), permiten prever que esta especie puede representar a corto plazo una importante amenaza fitosanitaria (SENASICA 2015). Por tanto, contar con diagnóstico preciso y oportuno, será crítico en la prevención de invasión de la especie exótica $X$. glabratus.

El diagnóstico tradicional por caracteres morfológicos específicos de especies del género Xyleborus generalmente es difícil, debido a la similitud morfológica existente entre las especies, o porque los ejemplares no cuentan con la calidad requerida para su determinación (Kuerová et al.
2009, Pérez-De La Cruz et al. 2009, Pérez et al. 2015a). Dados estos inconvenientes se han desarrollado técnicas moleculares que permiten determinar con rapidez y sensibilidad la identidad de los organismos (Cognato et al. 2011), mediante el uso de marcadores moleculares. En este sentido, Chang et al. (2013) identificaron 32 especies del género Xyleborus al desarrollar códigos de barras mediante una PCR dirigida a dos regiones del gen mitocondrial Citocromo Oxidasa subunidad I (CO1). También se han empleado técnicas moleculares para definir la filogenia de Xylosandrus (Dole et al. 2010), y se ha hecho uso de la secuenciación de proteínas de la subunidad grande del ribosoma (LSU rADN), para la determinación de los hongos asociados con $X$. glabratus (Harrington et al. 2010).

La PCR ha ganado aceptación debido a su rapidez, sensibilidad y reproducibilidad en la determinación específica por lo que en este estudio se propuso como objetivo validar y estandarizar esta herramienta como elemento de diagnóstico de especies de Xyleborus.

\section{MATERIALES Y MÉTODOS}

Material biológico. Se utilizaron individuos donados a partir de la colección entomológica del Centro Nacional de Referencia Fitosanitario (CNRF) y del Colegio de Postgraduados, Campus Montecillo, México, previamente identificados mediante caracteres taxonómicos por el personal del CNRF, Dr. Armando Equihua Martínez y M.C. Mauricio Pérez Silva. Las muestras incluían individuos pertenecientes al género Xyleborus, colectados en diferentes trampas con luz instaladas en plantaciones de cacao y aguacate en Tabasco y Michoacán, México y Florida, EUA (Cuadro 1) y preservados en seco o eta-

Cuadro 1. Especies del género Xyleborus, utilizados para la extracción de ADN y amplificación del gen $\mathrm{CO} 1$, colectados en trampas de luz instaladas en plantaciones de cacao y aguacate en Tabasco y Michoacán, México y Florida, EUA.

\begin{tabular}{lllc}
\hline \multicolumn{1}{c}{ Especie } & \multicolumn{1}{c}{ Hospedero } & \multicolumn{1}{c}{ Lugar de colecta } & Fecha de colecta \\
\hline X. affinis (Eichhoff, 1868) & Aguacate & Uruapan, Mich. & 2014 \\
X. ferrugineus (Fabricius, 1801) & Cacao & Cárdenas, Tab. & 2007 \\
X. glabratus (Eichhoff, 1877) & Aguacate & Florida, USA & 2007 \\
X. horridus (Eichhoff, 1869) & Cacao & Cárdenas, Tab. & 2007 \\
X. intrusus (Blandford, 1898) & Cacao & Cárdenas, Tab. & 2007 \\
X. spinulosus (Blandford, 1898) & Cacao & Teapa, Tab. & 2007 \\
X. volvulus (Fabricius, 1775) & Cacao & Cárdenas, Tab. & 2012 \\
\hline
\end{tabular}


nol a $70 \%$. En todos los individuos se documentaron las características morfológicas distintivas de cada ejemplar utilizando un fotomicroscopio Tesovar (Carl Zeiss), para posteriormente realizar la extracción de $\mathrm{ADN}$.

Extracción de ADN a partir de especímenes de Xyleborus. Previo a la extracción de ADN, los especímenes se lavaron, tres veces con $500 \mu \mathrm{L}$ de TAE $1 \mathrm{X}$ durante 5 min, para eliminar el etanol. Cada espécimen se colocó en una sanita estéril, y se dejó secar por $48 \mathrm{~h}$. El ADN se extrajo individualmente de hembras adultas del género Xyleborus, empleando el kit de Qiagen DNeasy ${ }^{\circledR}$ mericom Food [69514] (DMF) (Qiagen 2010) siguiendo las instrucciones marcadas por el fabricante, con las siguientes modificaciones: 1) se utilizó un solo espécimen por tubo de reacción, macerando el insecto con $100 \mu \mathrm{L}$ de buffer de lisis y con la ayuda de un micropistilo (Diagger Company); 2) el volumen de los reactivos fue de 0.3 $\mu \mathrm{L}$ de Proteinasa K; $100 \mu \mathrm{L}$ de cloroformo, buffer PB y AW2; y 3) el ADN se recuperó con $20 \mu \mathrm{L}$ de buffer EB. En esta primera etapa se realizaron extracciones de dos ejemplares de $X$. affinis y dos de $X$. volvulus. Una vez verificada la presencia de ADN mediante la medición por espectrofotometría $\left(\right.$ Nanodrop $\left.^{\circledR}\right)$, se realizó la extracción con ejemplares representantes de siete especies.

Estandarización y validación del PCR. La estandarización y validación se realizó con ejemplares del género Xyleborus y para comprobar que se obtuvo la calidad mínima de ADN extraído para las reacciones de PCR se realizaron reacciones de amplificación con dos pares de oligos dirigidos al gen $\mathrm{CO} 1$, mediante el uso de los oligos externos reportados por Cognato y Sperling (2000): CI-J-2183 5'-CAACATTT ATTTTTGATTTTTTGG-3' y TL2-N-3014 5'-TCCAATGCACTAAT CTGC CATATTA-3' y los oligos internos reportados por Chang et al. (2013) J2210 5'-TCGCAT ATTATTAGGCAAGAAAGAG-3' y N2739 5' -AGAAAT GTTGTG GGAAGAAAG-3. La primera amplificación generó un fragmento de aproximadamente $1300 \mathrm{pb}$, y la segunda amplificación un fragmento de $\sim 500 \mathrm{pb}$. En la estandarización de la amplificación se evaluaron dos polimerasas comerciales de Promega (Go Taq ${ }^{\circledR}$ Flexi (M8295) y Go Taq ${ }^{\circledR}$ (M3005)) (Promega 2015), se ajustaron las temperaturas de alineamiento, así como la concentración de los componentes de la reacción (Bolívar et al. 2014). La reacción de PCR se optimizó para realizar en un volumen final de entre $10 \mathrm{y}$ $15 \mu \mathrm{L}$ por reacción.

Límite de detección. Fue pertinente establecer el límite de detección (LD) de las muestras de ADN obtenido con- siderando que el tamaño de los especímenes de Xyleborus es muy pequeño $(2.3 \mathrm{~mm}$ ) excepto $X$. horridus $(4 \mathrm{~mm})$ (Pérez et al. 2015a), y el peso no llega al mínimo sugerido por el kit comercial $(200 \mathrm{mg})$, por lo que existía la posibilidad de extraer ADN insuficiente para la reacción de PCR. Para establecer el límite de detección se realizaron diluciones seriales con un factor de 10 a partir de las muestras de PCR amplificadas. Así se realizaron diluciones desde $10^{-1}$ hasta $10^{-5}$ (Jiménez et al. 2014), que correspondieron a $780 \mathrm{ng} / \mu \mathrm{L}$ (ADN sin diluir) y 0.078 $\mathrm{pg} / \mu \mathrm{L}$, respectivamente.

Posteriormente los productos de PCR se fraccionaron en un gel de agarosa a $1.5 \%$ que se tiño con bromuro de etidio $(0.5 \mu \mathrm{L})$. La electroforesis se realizó a $90 \mathrm{~V}$ por 40 min en una solución amortiguadora TAE $1 \mathrm{X}(4.68 \mathrm{~g}$ de Tris Base $1 \mathrm{M} \mathrm{pH} \mathrm{8.0;1.14} \mathrm{mL} \mathrm{de} \mathrm{ácido} \mathrm{acético} \mathrm{glacial} \mathrm{y}$ $2 \mathrm{~g}$ de EDTA 0.5M). Para su visualización se comparó el tamaño del amplicon con el marcador de peso molecular (MM) de $100 \mathrm{pb}$.

Análisis molecular. Los productos de la PCR obtenidos a partir de 26 individuos del género Xyleborus se limpiaron siguiendo el proceso establecido en el kit Wizard ${ }^{\circledR} \mathrm{SV}$ Gel y PCR Clean-Up System (Promega ${ }^{\circledR}$ Cat: a9282) de acuerdo con las recomendaciones del proveedor. Este producto fue enviado a secuenciar al Instituto de Biotecnología de la UNAM (IBT UNAM) con los oligos internos (J2210 y N2739). Los electroferogramas se editaron y analizaron mediante un alineamiento por homología utilizado el programa Clustal $W$ (http://www.ebi.ac.uk/Tools/msa/clustalo/) implementado en la versión 6.0 del programa Mega (Tamura et al. 2013).

\section{RESULTADOS}

Identificación morfológica. Se corroboró la identidad de los ejemplares de acuerdo a la clave propuesta por Pérez et al. (2015a). La diferenciación de especies del género se hizo con base en caracteres morfológicos como las crenulaciones del pronoto, forma del mazo antenal, forma y ornamentaciones del margen anterior del pronoto, dientes en la protibia y declive elitral, entre otros (Fig. 1) (Wood 1986, Rabaglia et al. 2006, Pérez et al. 2015a). Además, las características distintivas de Xyleborus affinis, $X$. ferrugineus, $X$. glabratus, $X$. horridus, $X$. intrusus, $X$. spinulosus y $X$. volvulus (Fig. 1) fueron validadas por el M. en C. Pérez, especialista en el grupo, y que coincidieron con las reportadas en la literatura (Pérez-De La Cruz et al. 2009, Atkinson et al. 2013, Pérez et al. 2015a). 


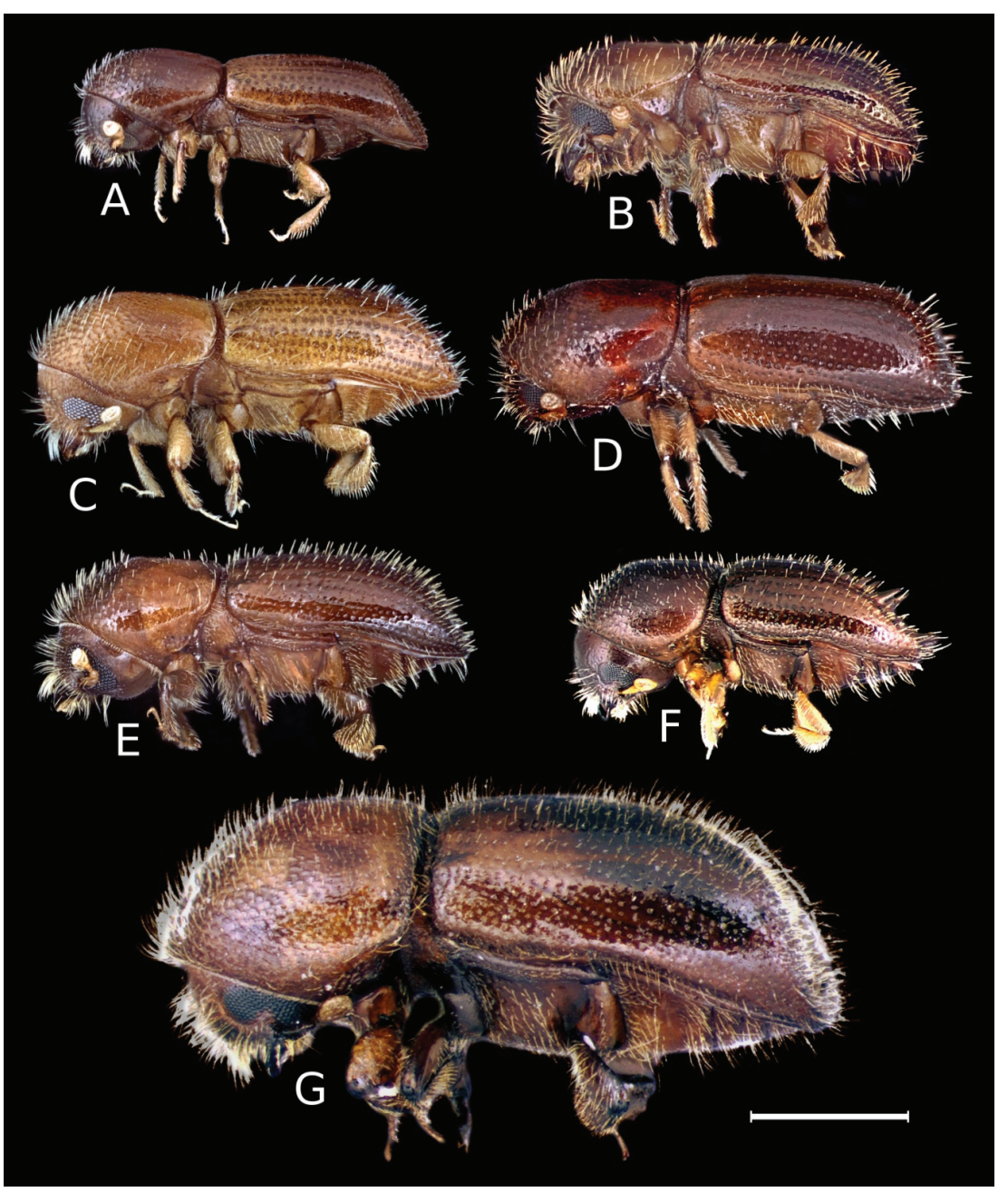

Figura 1. Vista lateral de especies de Xyleborus. A) Xyleborus glabratus, B) Xyleborus affinis, C) X. ferrugineus, D) X. intrusus, E) X. volvulus, F) X. spinulosus y G) X. horridus. Escala: $1 \mathrm{~mm}$.

Extracción de ADN a partir de especímenes de Xyleborus. Aun cuando el kit DFM de Qiagen ${ }^{\circledR}$ no es específico para insectos y no estaba documentado su uso para este grupo de organismos, resultó adecuado en la extracción de ADN a partir de un individuo de Xyleborus, de manera sencilla, rápida, reproducible con calidad y cantidad suficiente para realizar reacciones de amplificación del ADN. El total de las extracciones amplificaron un fragmento de $\sim 500 \mathrm{pb}$ correspondientes a una sección del gen CO1 (Fig. 2). Una utilidad práctica del kit DMF Qiagen ${ }^{\circledR}$ fue el hecho de que la mayoría de las muestras procesadas tenían una antigüedad de ocho años de conservación en etanol a $70 \%$ o en seco, como el caso de $X$. glabratus, por lo que su aplicación en material almacenado es evidente, sin

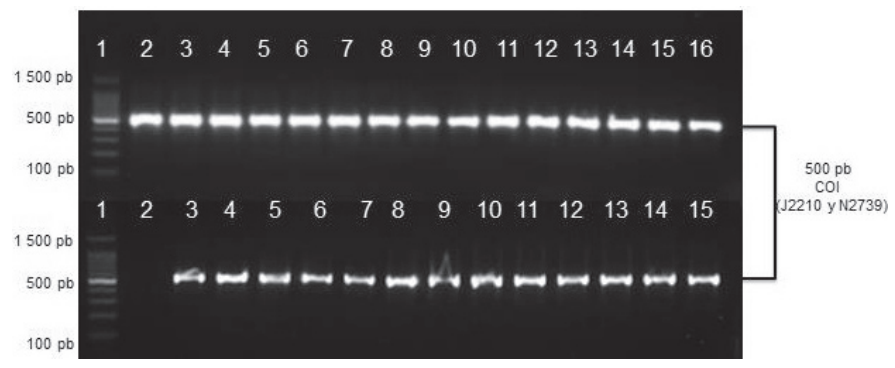

Figura 2. Amplificación del ADN extraído de diferentes muestras de Xyleborus con el Kit DMF Qiagen ${ }^{\circledR}$ dirigido al gen COI. Arriba: 1) Marcador de peso molecular (100 pb Ladder), 2-7) X. affinis, 8-13) X. ferrugineus, 14-16) X. horridus. Abajo: 1) MPM, 2) control negativo, 3) $X$. glabratus, 4-6) $X$. intrusus, 7-9) $X$. spinulosus, y 10-15) $X$. volvulus. 
Cuadro 2. Rendimiento promedio de ADN extraído de diferentes especies de Xyleborus con el Kit DMF Qiagen ${ }^{\circledR}$ dirigido al gen CO1.

\begin{tabular}{lcc}
\hline \multicolumn{1}{c}{ Especies } & Año de colecta & Rendimiento ng/ $\mu \mathrm{L}$ \\
\hline$X$. affinis & 2014 & 61.1 \\
X. volvulus & 2012 & 48.5 \\
X. horridus, X. spinulosus, X. intrusus, X. glabratus, X. ferrugineus & 2007 & 10.46 \\
\hline
\end{tabular}

embargo, se observó mejor rendimiento de ADN en las muestras con menor tiempo de preservación (Cuadro 2).

Estandarización y validación de la PCR. El ADN obtenido mediante el kit DMF Qiagen ${ }^{\circledR}$ fue evaluado en su calidad para realizar una reacción de amplificación. Antes de realizar dicho procedimiento se probaron las condiciones de amplificación debido a que algunas amplificaciones iniciales no tuvieron la reproducibilidad esperada, por lo que se procedió a estandarizar las condiciones de amplificación.

Se evaluaron dos polimerasas comerciales, varias temperaturas de alineamiento y diferentes concentraciones de cada uno de los componentes de la mezcla de reacción.

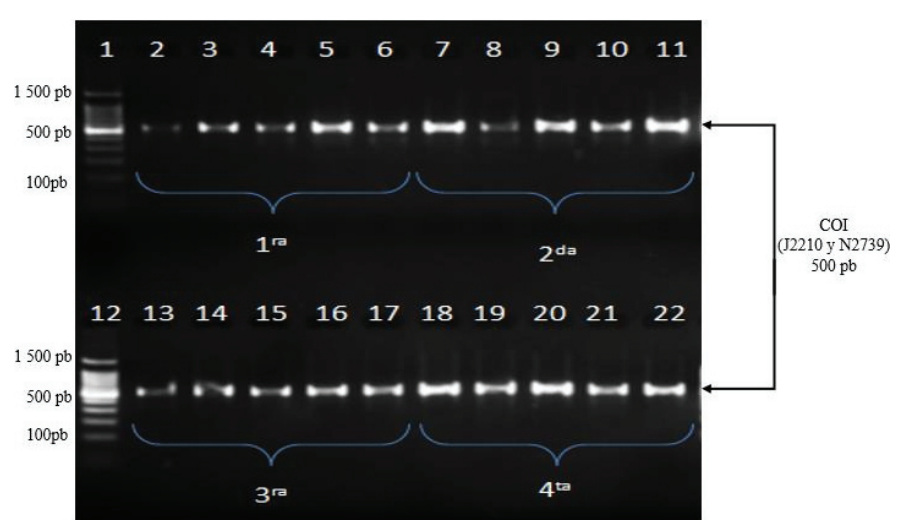

Figura 3. Reproducibilidad de la PCR-anidada, de acuerdo a las condiciones previamente estandarizadas y validadas. 1 y 12) MM 100 pb; 2-6) 1er ensayo del PCR con cinco repeticiones; 7-11) 2do ensayo del PCR con cinco repeticiones; 13-17) 3er ensayo del PCR con cinco repeticiones; 18-22) 4to ensayo del PCR con cinco repeticiones.
Cuadro 4. Optimización de la reacción de la PCR en volumen de 15 $\mu \mathrm{L}$ con la enzima Go $\mathrm{Taq}^{\circledR}$ (M3005).

\begin{tabular}{llc}
\hline \multicolumn{1}{c}{ Reactivos } & \multicolumn{1}{c}{ Concentración final } & 1X $(\mu \mathrm{L})$ \\
\hline Agua HPLC & & 6.3 \\
Buffer PCR 5X & $1 \mathrm{X}$ & 3.0 \\
dNTP's 10mM & $200 \mu \mathrm{M}$ & 0.3 \\
Oligo Forward 10mM & $200 \mu \mathrm{M}$ & 0.3 \\
Oligo reverse 10mM & $200 \mu \mathrm{M}$ & 0.3 \\
Taqpolimerasa 5U/ $\mu \mathrm{L}$ & $2 \mathrm{U}$ & 0.24 \\
Muestra ADN & $10-50 \mathrm{ng} / \mu \mathrm{L}$ & 3.0 \\
Volumen final & $15 \mu \mathrm{L}$ & \\
\hline
\end{tabular}

Una vez evaluados los diferentes parámetros se definieron las condiciones que dieron como resultado alta reproducibilidad en las amplificaciones (Fig. 3) (Cuadro 3). La reacción de amplificación se estandarizó para un volumen final de $15 \mu \mathrm{L}$ (Cuadro 4).

Análisis molecular. El segmento amplificado correspondió a $\sim 500 \mathrm{pb}$ del gen CO1. Se observó $100 \%$ de homología entre las secuencias de la misma especie, asimismo, se determinaron los especímenes con base en las características morfológicas distintivas. Las secuencias consenso fueron analizadas por homología y depositadas en el GenBank a través de la aplicación BLAST (Cuadro 5).

Puesto que las amplificaciones se realizaron a partir de especies identificadas taxonómicamente para dar certidumbre, se realizaron las secuenciaciones de cada amplificación por triplicado. Con la secuencias consenso obtenidas de las tres secuencias, el análisis BLAST in-

Cuadro 3. Programa de amplificación para especies del género Xyleborus, citado por Chang et al. (2013), con modificación en la temperatura de alineación.

\begin{tabular}{llccc}
\hline & \multicolumn{1}{c}{ Pasos de amplificación } & Temperatura & Tiempo & Ciclos \\
\hline 1 & Desnaturalización inicial & $94^{\circ} \mathrm{C}$ & $5 \mathrm{~min}$ & 1 \\
2 & Desnaturalización del ADN molde & $94{ }^{\circ} \mathrm{C}$ & $30 \mathrm{~s}$ & \\
3 & Hibridación de los oligonucleótidos & $52.5^{\circ} \mathrm{C}$ & $45 \mathrm{~s}$ & 35 \\
4 & Extensión de la copia & $72^{\circ} \mathrm{C}$ & $45 \mathrm{~s}$ & \\
5 & Extensión final & $72^{\circ} \mathrm{C}$ & $10 \mathrm{~min}$ & 1 \\
\hline
\end{tabular}


Cuadro 5. Número de acceso de secuencias consenso para especies del género Xyleborus derivadas de este estudio y depositadas en el GenBank.

\begin{tabular}{llc}
\hline \multicolumn{1}{c}{ Especie } & \multicolumn{1}{c}{ Origen } & $\begin{array}{c}\text { Número de acceso } \\
\text { al GenBank }\end{array}$ \\
\hline Xyleborus affinis & Uruapán, Michoacán & KX825867 \\
& & KX825868 \\
& & KX825869 \\
Xyleborus ferrugineus & Cárdenas, Tabasco & KX825870 \\
& & KX825871 \\
& & KX825872 \\
& & KX825873 \\
Xyleborus glabratus & Florida, USA & KX825879 \\
Xyleborus horridus & Cárdenas, Tabasco & $*$ \\
Xyleborus intrusus & Cárdenas, Tabasco & $*$ \\
Xyleborus spinulosus & Cárdenas, Tabasco & $*$ \\
Xyleborus volvulus & Cárdenas, Tabasco & KX825875 \\
& & KX825876 \\
& & KX825877 \\
& & KX825878 \\
\hline
\end{tabular}

* En proceso de liberación por ser las primeras secuencias del gen CO1 depositadas en el GenBank para las especies.

dicó que para $X$. affinis se obtuvo una homología de $92 \%$ con una de las secuencias para $X$. affinis presentes en el GenBank (AF187138.1); las secuencias generadas para $X$. spinulosus, $X$. horridus e $X$. intrusus, presentaron baja homología contra otras especies por no haber secuencias para CO1 disponibles para estas especies. Por tanto, estas son las primeras secuencias del gen $\mathrm{CO} 1$ depositadas en el GenBank para estas tres especies. La secuencia generada para $X$. ferrugineus presentó una identidad de $79 \%$ contra la secuencia JX424246.1 de la misma especie.

\section{DISCUSIÓN}

El diagnóstico tradicional de especies del género Xyleborus por caracteres morfológicos específicos generalmente es difícil, debido a la similitud morfológica existente entre las especies. No obstante, mediante el uso de claves específicas como la propuesta por Pérez et al. (2015a) fue posible reconocer las características distintivas de las especies estudiadas.

En este estudio, se confirma que el uso del kit de extracción Qiagen DNeasy ${ }^{\circledR}$ mericon Food (69514) para obtener material genético de especies del género Xyleborus (preservados hasta por ocho años, en seco ó en alcohol a
$70 \%$ ) fue confiable y sensible pues el ADN extraído de un ejemplar de Xyleborus fue suficiente (10.46 a $61.1 \mathrm{ng} / \mu \mathrm{L})$ para obtener el producto de la amplificación esperado. El método permitió también obtener ADN de calidad, partiendo incluso de solo una parte del individuo (X. horri$d u s$ tamaño promedio $4.0 \mathrm{~mm}$ ) debido a que se obtuvo buen producto de amplificación de la cabeza, abdomen y apéndices. Este resultado coincide con lo reportado por autores quienes señalan que la calidad del ADN extraído mediante el uso del kit DFM se debe principalmente a la utilización de CTAB (Bromuro de Cetil-Trimetil-Amonio); reactivo que ayuda a la eliminación de polisacáridos proteínas y polifenoles de la muestra, lo cual mejora la calidad del ADN extraído (Marzachi et al. 1998, Reineke et al. 1998, Kušec et al. 2015, Schwerer et al. 2015). Contrario a ello Volk et al. (2014), señalan que el bajo rendimiento de ADN (cantidad y calidad) obtenido con el kit DMF, junto con el alto costo, en comparación con otras metodologías, pone en duda el uso práctico del kit. No obstante, se debe considerar que la obtención de material genético para un análisis molecular, ya sea para confirmar identidad como en este trabajo, o para estudios filogenéticos, de diversidad o ecología molecular depende, con frecuencia, del tipo, tamaño y tiempo de preservación del material (Barrio-Caballero 2012, Martínez de la Puente et al. 2013), debido a que generalmente se obtienen mejores resultados con ejemplares grandes, frescos y correctamente conservados (Cornejo et al. 2014).

Otro factor que repercutió en la calidad de la amplificación fue la temperatura de alineamiento $(\mathrm{Tm})$. Si bien se observó amplificación de calidad en las temperaturas de $49.1,50.7$ y $52.5^{\circ} \mathrm{C}$, valores cercanos a la $\operatorname{Tm}\left(47^{\circ} \mathrm{C}\right)$ utilizada por Chang et al. (2013) en la PCR para el diagnóstico de Xyleborus, los mejores resultados se lograron con una $T m$ de $52.5^{\circ} \mathrm{C}$ debido a que se generó un amplicon de mejor calidad en comparación con el resto de las temperaturas evaluadas (Bolívar et al. 2014, Cornejo et al. 2014).

Asimismo, los ensayos realizados para determinar la concentración de los dNTP's y oligos indicaron que la amplificación de mejor calidad se logró con la concentración de $200 \mu \mathrm{M}$. Estos valores coinciden con los recomendados por diversos autores, quienes señalan que la concentración tanto de dNTP's y oligos debe usarse con precisión debido a que un exceso o déficit puede ocasionar errores en la PCR (Bolívar et al. 2014, Suzuki y Yao 2014). Al respecto Cornejo et al. (2014), y Bolívar et al. (2014), reportan que la presencia de dímeros, ocasionados por exceso de reactivos $\left(\mathrm{MgCl}_{2}, \mathrm{dNTP}\right.$ 's 
y oligos) compromete el éxito en la amplificación del ADN molde.

Los ensayos realizados revelaron la estandarización y validación de la técnica al observarse una alta reproducibilidad en la amplificacion de las repeticiones de la PCR; es decir, la existencia de $100 \%$ de probabilidad de encontrar el mismo resultado entre las muestras. Estos hallazgos coinciden con autores quienes refieren la alta reproducibilidad de la técnica de PCR y sus variantes como una herramienta confiable en la detección de diferentes organismos, además de su alta sensibilidad y rapidez; características que le confieren gran ventaja frente a los métodos convencionales (Villarreal et al. 2008, Cornejo et al. 2014, Hernández y Guzmán 2014).

Aun cuando la identificación morfológica de las especies en este estudio, coincide con los caracteres diacríticos para cada especie de acuerdo a las claves taxonómicas y se dio certidumbre a las secuencias obtenidas, ya que se realizaron al menos tres réplicas de secuenciación para cada especie, se presentaron algunas inconsistencias y bajo porcentaje de homología respecto a la información reportada en el GenBank. Por ejemplo, las secuencias de este estudio correspondientes a $X$. ferrugineus presentaron homología con Xyleborus schaufussi (Blandford, 1894) (AB588939.1) con una identidad y cobertura de $83 \%$ y $99 \%$, respectivamente, especie que de acuerdo con Pérez et al. (2015a y b) no está reportada para el país, aspecto que pone en duda la identidad taxonómica de la especie. Por otro lado, en la base de datos solo esta reportada una secuencia para $X$. ferrugineus (JX424246.1) para el gen $\mathrm{CO} 1$, sin embargo, la información no es homologa a la secuencia obtenida para esta especie en el presente estudio. La no coincidencia en secuencias quizás se deba a una determinación errónea, de origen, de la especie y secuencia disponible en el GenBank, puesto que los especímenes que se trabajaron en este estudio fueron determinados con base en clave específica para especies mexicanas, las características distintivas de la especie fueron corroboradas por los especialistas y se revisaron varios especímenes. Algo similar, se presentó con las secuencias para $X$. affinis, $X$. volvulus y $X$. glabratus reportadas por Cognato et al. (2011), pues no hubo coincidencia con las reportadas en el presente estudio. La única secuencia donde se encontró concordancia en $93 \%$ y $100 \%$ de cobertura entre la información encontrada en este trabajo con la reportada en el GenBank fue para $X$. affinis con numero de acceso AF187138.1; sin embargo, no se encontró artículo publicado relacionado que permitiera conocer si previo al análisis molecular se corroboró la determinación morfológica de la especie. Asimismo, no se encontraron secuencias en la base de datos NCBI para confrontar la información de las especies de $X$. horridus, $X$. intrusus y $X$. spinulosus, de modo que las secuencias derivadas de este estudio se constituyen en los primeros registros fiables para dichas especies. Los números de acceso al GenBank de las mismas se anotan en el Cuadro 5.

Aun cuando se tiene un avance en el conocimiento y se cuenta con la técnica de PCR anidada para la detección rápida, sensible y confiable de especies del género Xyleborus es necesario ampliar las pruebas a otras especies para conocer con precisión los alcances de la herramienta y obtener información que permita la identificación veraz y oportuna de especies del género Xyleborus en cualquier estadio de su ciclo de vida.

\section{CONCLUSIONES}

La implementación del kit DMF fue apta para la obtención de material génico de especies del género Xyleborus en un menor tiempo y con la calidad adecuada, lo que permite su amplificación mediante PCR-anidada.

El método permitió procesar un solo insecto por extracción, y obtener material genético de muestras de varios años de preservación. Se estandarizó, validó y optimizó la técnica de PCR-anidada con alta reproducibilidad, aportando resultados de mayor confiabilidad permitiendo la correcta identificación molecular de las especies evaluadas. Se obtuvo la secuenciación parcial del gen $\mathrm{CO} 1$ para Xyleborus affinis, $X$. ferrugineus, $X$. glabratus, $X$. horridus, $X$. intrusus, $X$. spinulosus y $X$. volvulus. De esta manera el implementar esta metodología para el diagnóstico de especies Xyleborus constituye una alternativa de diagnóstico complementaria a la tradicional.

AGRADECIMIENTOS. Al Consejo Nacional de Ciencia y Tecnología (CONACYT) por el apoyo económico para la realización de estudios de Maestría del primer autor, al personal del CNRF, al Dr. Armando Equihua Martínez y Dr. Francisco Javier Avendaño Gutiérrez por los ejemplares proporcionados, al M.C. Mauricio Pérez Silva por la corroboración taxonómica de los ejemplares y al M.C. Jorge Valdez Carrasco por el apoyo técnico en el trabajo fotográfico.

\section{LITERATURA CITADA}

Atkinson T. H., Carrillo, D., Duncan, R. E. \& Peña, J. E. 2013. Occurrence of Xyleborus bispinatus (Coleoptera: Curculionidae: Scolytinae) Eichhoff in southern Florida. Zootaxa, 3669, 96-100. 
Barrio-Caballero, P. A. 2012. Revisión de métodos de extracción de $\mathrm{ADN}$ a partir de restos óseos en el laboratorio forense. Revista Española Médico Legal, 39, 54-62.

Bolívar A. M., Rojas, A. \& García-Lugo, P. 2014. PCR y PCR-Múltiple: parámetros y protocolos de estandarización. Avances en Biomedicina, 3, 25-33.

Chang H., Liu, Q., Hao, D., Liu, Y., An, Y., Qian, L. \& Yang, X. 2013, DNA barcodes and molecular diagnostics for distinguishing introduced Xyleborus (Coleoptera: Scolytinae) species in China. Mitochondrial ADN. Early Online, 1-7.

Cognato A. I., Hulcr, J., Dole, S. A. \& Jordal, B. H. 2011, Phylogeny of haplo-diploid, fungus-growing ambrosia beetles (Curculionidae: Scolytinae: Xyleborini) inferred from molecular and morphological data. Zoologica Scripta, 40, 174186.

Cognato, A. I. \& Sperling, F. A. 2000. Phylogeny of Ips DeGeer species (Coleoptera: Scolytidae) inferred from mitochondrial cytochrome oxidase I DNA sequence. Molecular Phylogenetic Evolution, 14, 445-460.

Cornejo, R. A., Serrato D., A., Rendón A., B. \& Rocha M., M. G. 2014. Herramientas moleculares aplicadas en ecología: aspectos teóricos y prácticos. Secretaría de Medio Ambiente y Recursos Naturales (SEMARNAT). Instituto Nacional de Ecología y Cambio Climático (INECC), Universidad Autónoma MetropolitanaIztapalapa (UAM-I), 255 pp.

Dole, S. A., Jordal, B. H. \& Cognato, A. I. 2010. Polyphyly of Xylosandrus Reitter inferred from nuclear and mitochondrial genes (Coleoptera: Curculionidae: Scolytinae). Molecular Phylogenetics and Evolution, 54, 773-782.

FAO-IPPC 2007. NIMF $\mathrm{N}^{\circ}$ 2. Marco para el análisis de riesgo de plagas. Normas Internacionales para Medidas Fitosanitarias. Secretaría de la Convención Internacional de Protección Fitosanitaria. Disponible en: http://www.cosave.org/ sites/ default/files/ nimfs/cfd338f5bbd3cf63500f 97fbca 940633.pdf (Consulta: Mayo 2015).

Harrington T. C., Aghayeva, D. N. \& Fraedrich, S. W. 2010. New combinations is Raffaelea, Ambrosiella and Hyalorhinicladiella, and four new species from the redbay ambrosia beetle, Xyleborus glabratus. Mycotaxon, 111, 337-361.

Hernández, G., A. K. \& Guzmán B., M. M. 2014. Detección del virus del amarillamiento de los nervaduras de la hoja de la papa en diferentes órganos de Solanum tuberosum grupo Phureja cv Crio1la Colombia utilizando RT-PCR convencional y en tiempo real. Revista Colombiana de Biotecnología, 16, 74-85.

Jiménez A., Cortez, S., Duarte, L. Z., Martínez, M., Flórez, S. Y., Méndez, C., Granados, M. \& Villamizar, A. 2014. Estandarización de una PCR anidada para la identificación de Lawsonia intracellularis en porcinos. Spei Domus, 10, 23-29.

Kuerová Z., Li, Z. \& Hromádková, J. 2009. Morphology of nymphs of common stored-product psocids (Psocoptera: Liposcelididae). Journal Stored Products Research, 45, 54-60.

Kušec I. D., Radišić, Ž., Komlenić, M. \& Kušec, G. 2015. Comparison of commercial DNA Kits and traditional DNA extraction procedure in PCR detection of pork in dry/fermented sausages. ISSN 1330-7142. UDK: 637.52:636.082. Disponible en: http://bib. irb.hr/datoteka/779345.47_Djurkin_Kusec_ENGEDIT_20_07_ 2015.pdf (Consulta: Noviembre 2015).
Loera, F. 2014. The family Lauraceae in Mexico. In: Memoria del Simposio Internacional sobre Manejo y Control de Plagas Cuarentenarias (Caso: Escarabajos ambrosiales, Xyleborus glabratus y Euwallacea sp.) en el aguacatero. 3 al 7 de noviembre 2014. Xalapa, Veracruz, México. 62 pp.

Martínez-de la Puente J., Ruiz, S., Soriguer, R. \& Figueroa, J. 2013. Effect of blood meal digestion and DNA extraction protocol on the success of blood meal source determination in the malaria vector Anopheles atroparvus. Malaria Journal, 12, 109.

Marzachi, C., Veratti, F. \& Bosco, D. 1998. Direct PCR detection of phytoplasms in experimentally infected insects. Annals of Applied Biology, 133, 45-54. doi: 10.1111/j.1744-7348.1998.tb05801.x

Pérez, S. M., Equihua M., A. \& Atkinson, T. H. 2015a. Identificación de las especies mexicanas del género Xyleborus Eichhoff, 1864 (Coleoptera: Curculionidae: Scolytinae). Insecta Mundi, 0440, 1-35.

Pérez, S. M., Equihua M., A., Estrada V., E., Muñoz V., A.L., Valdez C., J.M., Sánchez E., J. \& Atkinson, T. H. 2015b. Sinopsis de especies mexicanas del género Xyleborus Eichhoff, 1864 (Coleoptera: Curculionidae: Scolytinae). Acta Zoológica Mexicana (n.s.), 31, 239-250.

Pérez-De La Cruz, M., Equihua M., A., Romero-Nápoles, J., Valdez-Carrasco, J. M. \& De La Cruz-Pérez, A. 2009. Claves para la identificación de escolítinos (Coleoptera: Curculionidae: Scolytinae) asociados al agro-ecosistema del cacao en el sur de México. Boletín del Museo de Entomología de la Universidad del Valle, 10, 14-29.

Promega 2015. Certificate of analysis GoTaq ADN polymerasa (M3005). Disponible en: https:// worldwide.promega.com/ /me$\mathrm{dia} /$ files/resources/protocols/product $\% 20$ information $\% 20$ sheets/ g/gotaq\%20ADN\%20polymerase\%20m300.pdf (Consulta: Agosto 2015).

Qiagen 2010. DNeasy ${ }^{\circledR}$ mericon TM Food Handbook for extraction of total nucleic acids from a range of food simple types. Disponible en: https://www.qiagen.com/hk/resources/resourcedetail?id $=\mathrm{d} 0 \mathrm{e} 372 \mathrm{~d} 7-6 \mathrm{f} 6 \mathrm{a}-415 \mathrm{e}-9 \mathrm{~d} 72-297 \mathrm{a} 53 \mathrm{~d} 95854 \&$ lang=en (Consulta: 2015).

Rabaglia R. J., Dole, S. A. \& Cognato, A. I. 2006. Review of American Xyleborina (Coleoptera: Curculionidae: Scolytinae) occurring north of Mexico, with an illustrated key. Annals of the Entomological Society of America, 99, 1034-1056.

Reineke A., Karlovsky, P. \& Zebitz C., P. W. 1998. Preparation and purification of ADN from insects for AFLP analysis. Insect Molecular Biology, 7, 95-99. doi: 10.1046/j.1365-2583.1998.71048.x.

Schwerer M. J., Vogl, S. \& Graw, M. 2015. Extraction of ADN from gastric content in different stages of digestion. Forense Science International: Genetics Supplement Series. Disponible en: http:// dx.doi.org /10.1016/ j.fsigss.2015.10.004 (Consulta: Noviembre 2015).

SENASICA. 2015. Escarabajo ambrosial del Laurel Rojo Xyleborus glabratus, Eichhoff (Coleoptera: Curculionidae: Scolytinae). Servicio Nacional de Sanidad, Inocuidad y Calidad Agroalimentaria. Secretaría de Agricultura, Ganadería, Desarrollo Rural, Pesca y Alimentación. México. 11 pp.

Suzuki, S. \& Yao, I. 2014 Isolation of nine polymorphic microsatellite loci from the burying beetle, Nicrophorus quadripunctatus (Coleoptera: Silphidae). Applied Entomology, 49, 493-497. 
Tamura K., Stecher, G., Peterson, D. \& Kumar, S. 2013. Mega 6: Molecular evolutionary genetics analysis version 6.0. Molecular Phylogenetics and Evolution, 30, 2725-2729.

Villarreal, J., Soto, Z., Pereira, N., Varela, L., Jaramillo, R., Villanueva, D. \& Mendoza, E. 2008. Reacción en cadena de la polimerasa para la detección de Salmonella sp. en leche en polvo. Op- timización del método en 12 horas. Salud Uninorte, 2, 216-225. Volk H., Piskernik, S., Kurinčič, M., Klančnik, A. \& Jeršek, B. 2014. Evaluation of different methods for DNA extraction from milk. Journal of Food and Nutrition Research, (2), 1-10.

Wood, S. L. 1986. A reclassification of the genera of Scolytidae (Coleoptera). Great Basin Naturalis Memoirs, 10, 126. 